\title{
Do We Have an Inborn Moral Sense?
}

\author{
Marilyn Walker \\ Marilyn Gisk Walker, 2067 Van Tuyl Place, McLean, VA, USA \\ Email: marilyn.gisk@gmail.com
}

Received 11 September 2014; revised 5 October 2014; accepted 18 October 2014

Copyright (C) 2014 by author and Scientific Research Publishing Inc.

This work is licensed under the Creative Commons Attribution International License (CC BY). http://creativecommons.org/licenses/by/4.0/

(c) (i) Open Access

\begin{abstract}
This paper reviews some recent work in the relationship between caring behavior among humans, an evolutionary adaptation necessary for survival of the species, and our moral sense of right and wrong. The investigation presents some of our current understandings; the question is part of ongoing work in neuroscience and evolutionary biology. Does caring behavior necessarily imply a moral sensibility?
\end{abstract}

\section{Keywords}

Altruism, Empathy, Emotional Contagion, Attachment Theory, Empathy Altruism

\section{Introduction}

This paper reviews some recent work in the areas of moral intuition and caring behavior among humans. Recent neurophysiological research has identified areas of the brain involved in caring behavior. Evolutionary biology, in conjunction with neuroscience, seems to have an agreed-upon hypothesis on how to care; i.e., bonding behavior evolved via natural selection. I look at some of the questions that caring behavior gives rise to. Where does it come from? What are the manifestations? How and when is it a force for good, or not? Does caring behavior necessarily imply a moral sensibility?

Many of the understandings in the scientific community are preliminary and open to revision. So any hypotheses I propose are exploratory and tentative. They may provide suggestions for further studies to help figure out the salient characteristics that cause one to act on behalf of another, even at times with negative consequences for oneself.

\section{Tentative Understandings}

Caring behaviors in the human species are built-in; they are part of our evolutionary heritage and are often unconscious. As described in the body of the paper, the automatic identification with others, what Pfaff calls "the blurring mechanism”, frequently results in moral behavior; e.g., a mother caring for her crying infant. But there 
is a distinction between caring and moral behavior. The first is a given; the latter is not. For we are also capable of heinous behavior; just watch the news or read the newspaper.

Moral behavior can result from both unconscious impulses and conscious decision making. It is easy to be moral when the impulse is not thwarted, or — better yet—reinforced; e.g., a mother cares for her new infant. It is not easy when social forces or personal need interfere; e.g., a teen-ager is part of a crowd whose approval he wants; and the crowd is bullying a kid on the playground.

Increased conscious awareness allows for more choice in difficult moral situations. Both top-down and bottom-up processing are involved. The lower level, which is automatically activated by perceptual input, the "blurring mechanism", accounts for emotion sharing, the implicit recognition that others are like us. The top-down regulation, through the executive functions modulates low levels and adds flexibility, making the individual less dependent on the automatic external cues. The possibility for reappraisal of a situation and increased exercise of control seems to be dependent on the development of the prefrontal cortex, sometimes called the "executive suite", which continues to mature through adolescence (Decety \& Lamm, 2006: 1148-1151).

So the hopeful understanding is that we are created as human creatures to care about others. And we have the capability of using that caring for moral ends: "To do unto others as we would have them do unto us." We also have the capability of emotional reconsideration, so that the initial impulse need not prevail. We can review, rethink and then act. It seems that altruism is not just a self-serving way of expressing self-interest but may be a part of human nature.

\section{Evolutionary Perspective and Socialization}

Recent work in evolutionary biology indicates that both socialization and care for others are part of our evolutionary heritage via natural selection. According to Flanagan, "we are born as proto-moral, social beings.” Proto-moral in this context is the human capacity for morality as "a biological adaptation, having perhaps conferred a selective advantage on our hominin ancestors by enhancing social cohesion and cooperation" (FitzPatrick, 2012). Each newborn only survives to adulthood if given adequate care; groups only survive through cooperation. "Homo sapiens... as well as such closely related species, such as chimps and bonobos possess instincts and emotions that are proto-moral. We didn't create the relevant instincts and emotions, natural selection did. A genetic disposition toward fellow feeling for one's kin is more conducive to survival and reproduction than a disposition toward complete selfishness. Individuals possessed of at least a modicum of fellow feeling will do better at dating, mating and child rearing” (Flanagan, 2002: 296-297).

\section{Caring Behaviors}

In an attempt to understand what the various mechanisms are and how they work I will review the following behaviors: Emotional contagion, attachment, empathy, empathy altruism, altruism. In each case I will raise questions as to how the behaviors may or may not result in ethical behavior toward the other. I will start with altruism as that seems to underlie the other behaviors described.

\subsection{Altruism}

\subsubsection{Characterization}

Donald W. Pfaff describes altruism as "The Golden Rule", unselfish behavior; i.e., to do unto others as you would have them do unto you. He claims it to be both universal among humans and also manifest in other species (Pfaff, 2007: 14). Others define altruism differently. For Verplaetse, for example, an act of altruism requires not only unselfish behavior, but behavior which "reduces the evolutionary fitness of the doer and increases the fitness of the receiver" (Verplaetse, 2009: 16).

Pfaff sees altruism as a neurological adaptation of the mechanisms that support maternal-infant bonding that then are adapted for more general social relationships. His thesis is that many of the "brain mechanism which evolved to facilitate reproduction have subsequently become available to support a much wider variety of friendly, support behaviors that have nothing to do with sex or parenting... [They] are at the service of more complex social relationships...needed to maintain the Golden Rule” (Pfaff, 2007: 97-98). We follow the Golden Rule; i.e., behave in an ethical manner toward others as a transference of the evolutionary mother-child bonding behavior to more general and expansive uses. 
The hormone oxytocin plays a critical role in the mother-child relationship; it increases bonding and trust and reduces fear; it "encourages the onset of maternal behavior", stimulating contractions of the uterus and the ejection of milk from the mammary glands and may help "to decrease fear" and anxiety after pregnancy. Oxytocin is released from the hypothalamus and transmitted to the lower brain. An experiment at Rockefeller University blocked "the normal action of the hormone...[with the result that] it lowered the level of maternal behavior" (Pfaff, 2007: 101-102).

But other hormones are also critical. For there is no single hormone and no single place in the brain devoted to moral understanding or behavior As indicated earlier, neural processing that developed initially for survival of the group is available now in humans for more complex processing. Neural pathways that already exist are multi-functional and new pathways and capabilities are added upon existing ones; so that, according to Pfaff, "The brain does not have a [single] signaling circuit dedicated to ethics...[rather it has] mechanisms to make use of circuits that are already there" (Pfaff, 2007: 4). And according to De Schrijver, the circuits that support moral intuition, like most of the structure and function of the human brain are innate, guided by subconscious modular processes that are the result of natural selection (De Schrijver in Verplaetse, 2009: 258-261).

Pfaff hypothesizes that the mechanism at play in altruism is a blurring of identity between the self and the other, which takes place in the cerebral cortex. The loss of information, the blurring, causes the other's identity [to become] less easy to discriminate...from oneself. The merging of the self with the other through, according to Pfaff, the blurring of the other's face is critical in empathy, identification, altruism. "When we recognize another as...nonthreatening, then it is [via] decreased social recognition that...[someone is lead] to obey the Golden Rule. A person momentarily forgets the difference between himself and the other, and as a result he complies with a universal ethical principle” (Pfaff, 2009:119).

\subsubsection{Possible Consequences}

The positive effects of the exercise of The Golden Rule are obvious. But if, as Pfaff claims, altruism results from a blurring mechanism, a diminution of processing, a loss of recognition of the other as distinct from oneself, then the awareness of the other as a separate human being is diminished. The altruistic behavior may demonstrate insufficient awareness of the other's needs; i.e., the altruism may be effective action for the giver (if she were in need) but not for the receiver.

Pfaff speculates on another possible negative consequence of the Golden Rule. In organized group violence, "the violence committed by an individual may actually reflect some kind of bonding with other members of the group," Loyalty may come into play; the gang member may commit "a violent act because he does not want to let down his comrades" (Pfaff, 2007: 148).

\subsection{Emotional Contagion}

\subsubsection{Characterization}

Emotional contagion, as defined by Decety and Lamm, is a form of somatic mimicry; i.e., "the tendency to automatically mimic and synchronize facial expressions, vocalizations, postures and movements with those of another person, and consequently to converge emotionally” (Decety \& Lamm, 2006: 1149). The mimicry is typically not conscious.

Emotional contagion may also exist in other species; and it is manifest in infants and children. Мacaca mulatta monkeys observed a fellow monkey in pain from electric shock. They could turn off the shocks by pressing a series of levers. "Presumably, they read the pain in their fellow's face, shared his distress and physiological arousal, and thus learned to act to reduce his suffering...[In other experiments] monkeys saved themselves and other monkeys from electric shock with equal alacrity” (Hatfield, Cacioppo, \& Rapson, 1994: 81). The authors speculate that emotional contagion was the major factor. Infants, from a few months after birth through first year of life, react to pain of others as though to themselves. When they see another child cry, the subject child cries. From around fourteen months to two plus years, children feel their own fingers to see if they hurt when someone else hurts his fingers. By two and a half years toddlers realize someone else's pain is not theirs.

It is a puzzling incongruity that "people....are able to 'feel themselves into' others emotional lives to a surprising extent" while being "oblivious to the importance of emotional contagion in social encounters, and unaware of how swiftly and completely they are able to track the expressions of others” (Hatfield et al., 1994: 82-83). 
In a recent study, forty-five judges viewed fifty one-minute clips of "a social interaction between debating partner. It was their job to decide how much the partners liked one another...The judges [when asked] thought that the most important factors in their decisions...[were] the targets proximity, frequency of smiling, and expressiveness." The result showed that the cues "judges actually used, however...were greatly influenced by synchrony" i.e., mimicry/synchrony. The authors speculate that "because primitive emotional contagion occurs automatically,...[people are] unaware of the power and ubiquity of the phenomenon” (Hatfield et al., 1994: 183-184). In conversation, "people tend automatically and continuously to mimic and synchronize their movements with the facial expressions, voices, postures, movements, and instrumental behaviors of others.” (Hatfield et al., 1994: 10).

\subsubsection{Possible Consequences}

In emotional contagion the emotion of the other is catching, it is transferred and becomes the subject's own. For example, "you can be infected by cheerfulness or hilarity, without knowing what it is about" (Decety \& Lamm, 2006: 1149). Decety and Lamm see primarily positive effects of emotional contagion. They point out that from an evolutionary perspective it "may have had survival value by helping humans to communicate...[that] It leads to more smooth interactions and increased liking." And further that it "also seems to contribute to our ability to perceive and understand others' pain."

Emotional contagion "allows one to feel oneself into the emotional life of the other". But given that emotional contagion frequently occurs without self-awareness, does it typically lead to awareness and action on behalf of the other? And, if so, will the action taken be appropriate to the other's needs since "you can be infected by the...mood of others without even being aware of them as distinct individuals?” (Zahavi \& Overgaard, 2012: 5-6).

In some circumstances nonconscious awareness of another's pain could cause an aversive reaction in the observer that will result in retreat. In Freudian terms, can this experience evoke "defense mechanisms that allow [the conscious mind]...to shield itself from painful unconscious information?” (Hatfield et al., 1994: 82-83). There are those who may just want to flee. One "fMRI study showed that observing fearful body expressions not only produces increased activity in brain areas associated with emotional processes but also in areas linked with representation of action and movement. Thus, the mechanism of fear contagion automatically prepares the brain for action” (Decety \& Lamm, 2006: 1149).

Another possible negative impact of emotional contagion is that it may lead a person infected by others' reactions to more easily be caught up in a mob situation; e.g., bullying a kid on a school yard. It can cause the individual to lose her identity and join the crowd. As Gustave Le Bon wrote (1896) in discussing crowd behavior, "feeling of membership within a crowd...contributed to an enlargement of the ego (a sense of power), a release of impulse, a sense of contagion, and heightened suggestibility...Individuals in the crowd mimic the actions of the leader, and this mimicry, once initiated, infects all in attendance” (Hatfield et al., 1994: 147).

\subsection{Attachment Theory}

\subsubsection{Characterization}

Attachment theory as described by Moll and Souza is based on the initial caring by a parent for an infant and of filial and pair-bonding. The initial bonding expands to emotional investment in an abstract object, norm or idea; e.g., willingness to die for my country. This extended attachment from parent-child to abstraction has the following characteristics: Attachment connections:

- Are relatively enduring;

- Are based on parent-infant, filial and pair-bonding associations;

- Evidence an emotional dependence on the object of attachment;

- Are a manifestation of prosocial moral emotions (other-suffering and praising);

- Support feelings of belongingness and shared social nature;

- Result in a sense of bereavement when the attachment is lost, leading to emotions of shame or guilt; Neuropeptides and neuromediators are involved (vasopressin, oxytocin, dopamine and peptide Y).

\subsubsection{Possible Consequences}

Attachment theory as described by Moll and Oliveira-Souza is an expansion from the initial care bonding of 
mother and child to a group or ideal. In itself, it lays the groundwork for reaction but does not effect it. In itself it is neither moral nor immoral. It depends on both the nature of the attachment; e.g., for gun control or identification with the NRA and on what other aspects are evoked when confronted with danger: Aversive action, support for victims, support for crowds. It may work against individual responsibility since group identification is paramount. Even something as trivial as adoption of dress-e.g., ragged jeans to show irreverence and autonomy-may “boost one’s acceptance within a social group....and therefore boost one's social status. This would facilitate and stabilize indirect reciprocity” (Moll and Oliveira-Souza in Verplaetse, 2009: 80-81).

\subsection{Empathy}

\subsubsection{Characterization}

Zahavi and Overgaard distinguish empathy from other forms of fellow-feeling and bonding. They claim that in true empathy "the experience...remains that of the other. The focus is on the other, and the distance between self and other is preserved and upheld” (Zahavi \& Overgaard in Decety, 2012: 6).

This level of bonding is "more sophisticated than the simple yoking of perception of the self and the other". Decety and Lamm call this capability the capacity for role taking or perspective taking. Perspective taking develops later than motor mimicry and emotional contagion..., possibly because it heavily draws on the maturation of executive resources... of the prefrontal cortex which continues to mature from birth to adolescence.

Both top-down and bottom-up processing are involved in the expression of empathy. The implication is that empathy by this understanding may involve more self-awareness than altruism (in Pfaff's description), emotional contagion, or attachment to a group or ideal.

The lower level which is automatically activated by perceptual input accounts for emotion sharing, which leads to the implicit recognition that others are like us. Executive functions, implemented in the prefrontal cortex, regulate both cognition and emotion, notably through selective attention and self-regulation. The meta-level is continuously updated by bottom-up information and, in return, controls the lower level by providing topdown input. Thus, top-down regulation, through executive functions, modulates low levels and adds flexibility, making the individual less dependent on external cues. The meta-cognitive feedback plays a crucial role in taking into account one's own mental competence in order to react (or not) to the affective states of others (Decety \& Lamm, 2006: 1148-1151).

Zahavi and Overgaard give a phenomenological account of empathy; [It] "denotes a basic, sui generis, form of intentionality, directed at other experiencing subjects as such... To have empathy with another person is in short to experience the psychological life of that person... But...that does not entail that the other's experience is literally transmitted to you. In basic empathy the focus is on the other, on his thoughts and feelings, and not on myself”. The emotion of the other differs from the way you would experience the emotion if it were our own. Empathy is and is not first-hand experience; it is both like and unlike perception. It is like perception in being direct, unmediated and noninferential... It is unlike perception is not being able to offer the fullest presence of the empathized experience-that presence is only available to the subject of the experience. Whereas emotional contagion is self-centered, empathy is essentially other-centered (Zahavi \& Overgaard, 2012: 7-10).

Empathy requires that "individuals must be able to disentangle their own feelings from the feelings... [of] others...to attribute mental states to the target. Self-awareness is a necessary condition for making inference about the mental states in others... In the case of empathy, affective sharing must be modulated and monitored by the sense of whose feelings belong to whom, and thus, agency is a crucial aspect that enables a selfless regard for the other rather than a selfish desire to escape aversive arousal” (Decety \& Lamm, 2006: 1154). Individuals who can regulate their own emotions are more likely to experience empathy, and also to act in morally desirable ways with others.

The "emotion regulation, under voluntary control (top-down processing) taps into executive function resources and operates in conjunction with other neural mechanisms... [to regulate ] the selection of [the] appropriate response and the inhibition of other less appropriate responses in empathetic connections." If emotion regulation does not maintain the separation necessary for effective evaluation and action, the cost might be too high and the identification with the other too painful. Then the empathetic observer might direct her attention elsewhere so as not to "pay attention to another's emotional state”.

A study cited by Decety and Lamm "investigated the distinction between empathic concern and personal distress using a set of ecological and extensively validated stimuli”. The participants watched a video of patients 
undergoing painful medical treatment and told either to "put themselves explicitly in the shoes of the patients ['imagine self'] or...to focus their attention on the feelings and reactions of the patients ['image other']". The results "confirmed previous social psychology findings that projecting oneself into an aversive situation leads to higher personal distress and lower empathetic concern, while focusing on the emotional and behavioral reaction of another's plight is accompanied by higher empathic concern and lower personal distress. Neuroimaging data are consistent with this finding” (Decety \& Lamm, 2006: 1152-1159).

\subsubsection{Possible Consequences}

Enhanced awareness of the other can lead to helping behavior, to the need for distraction, or to abuse. Empathy need not be used for moral ends. It also can be used deliberately for malevolent purposes. Empathic awareness "about the emotional or cognitive state of a competitor...[can be used] to harm" her (Decety \& Lamm, 2006: 1159).

But given that feelings of empathy involve executive functions of the prefrontal cortex and that empathy has a more conscious component than emotional contagion, there is a greater possibility that action motivated by empathy, true empathy without excessive self-reference, will be more effective in addressing the other person's needs than bonding actions previously described.

\subsection{Empathy Altruism}

\subsubsection{Characterization}

Batson defines the empathy-altruism hypothesis as, "empathic concern-other oriented emotion elicited by and congruent with the perceived welfare of others in need - [that] produces altruistic motivation - motivation with the ultimate goal of increasing the other's welfare by removing the need.” The definition assumes action on the part of the observer, which empathy by itself does not.

Batson says that he came to the study of empathy in trying to answer the question, "Is helping ever...motivated by concern for the needy, or is our motivation always and exclusively self-interested?” And he came to agree with the answer put forth by Piliavan and Chang:

"There appears to be a 'paradigm shift' away from the earlier position that behavior that appears to be altruistic, must, under closer scrutiny, be revealed as reflecting egoistic motives. Rather, theory and data now being advanced are more compatible with the view that true altruism-acting with the goal of benefiting another-does exist and is a part of human nature" (Batson in Decety, 2012: 46).

\subsubsection{Possible Consequences}

Batson cites both good and bad potential impacts of empathy-induced altruism. The good potential consequences are:

- It can produce more sensitive care for those in need;

- It can improve attitudes toward action on behalf of members of stigmatized group;

- It can increase cooperation.

But empathy-altruism can also be used with negative effects

- People can be motivated to avoid experiencing empathic concern; it is too hard. Batson cites the extreme effort involved; e.g., pedestrians confronted by homeless people may want to avoid fellow feeling;

- People can violate their own standards of fairness and justice by showing favor to those they feel empathetic toward against the common good;

- It can lead to inappropriate responses. Batson particularly cites paternalistic response that does not empower the receiver but keeps her in an inappropriate dependent position. (Batson support the generally accepted thesis that "empathic concern evolved as part of the parental instinct among higher mammals" (Batson in Decety, 2012: 46-50).

\section{Fear}

\subsection{Characterization}

Fear is an evolutionary adaptation in humans for self-preservation. Fear can change what a person sees or thinks he sees and it can act as an inhibiter of action. We may be afraid before we know it. Sensory stimuli reach our 
sensory receptors value free; "we know we are afraid only when the fear-producing stimuli reach the...amygdale” (Pfaff, 2007: 23). Confirmation of the role of the amygdala in fear is cited by Pfaff in a study of monkeys. Rhesus monkeys are afraid of both snakes and human intruders. Scientists injected "a small dose of a toxic chemical into the portion of the monkeys' amygdala called the central nucleus destroying this group of nerve cells". After the injection, the monkeys were much less afraid under the same circumstances (Pfaff, 2007: 26).

Pfaff cites a study of fear in two-year old children "When in distress, the children's tendency to freeze in place in mid-task was tightly correlated with their bodily reactions such as speeded-up heartbeat and elevated levels of stress hormones" (Pfaff, 2007: 37). Pfaff suggests that the reaction of freezing in place in response to fear "stems from the innate fear response that in nature...saves their hide from time to time; a stiff immobility would, for example, make small animals harder to detect against a visual background” (Pfaff, 2007: 41). Fear-producing stimuli may act upon us without our knowledge and prevent either awareness of another's need or effective action on her behalf.

Berns cites an experiment in which fear changes "what a person sees (or thinks he sees)” (Berns, 2008: 83). A subject successively was given a series of cards, each with a single line on the left and three lines to the right. The subject was asked to identify which of the three lines on the right was the same length as the one on the left. When alone, 95\% of the subjects performed without a single error. The experiment was repeated with a group of people in a room. Only one was the subject; the others were plants unbeknownst to the subject. Answers were given out loud and the plants answered incorrectly much of the time. In that situation only one-fourth of the subjects answered correctly $100 \%$ of the time. "Most subjects caved to group pressure about one-third of the time” (Berns, 2008: 91). Obviously the subjects were influenced by others' judgment. Did the subjects perceive the lines differently or did they perceive them and then change their decision? As Berns asks, "Can other people change what you see?” (Berns, 2008: 93).

Subjects were given a new task: To turn two 3 dimensional figures around to see if they were the same. Alone $86 \%$ of the subjects did so correctly; in a group, with the others giving incorrect answers, 59\% correctly identified the congruent figures. An fMRI study showed that the visual processing areas; i.e., in the visual, parietal and temporal regions were very active when the person looked at the screen. When the subject "capitulated to the group and the group was wrong...[there was] more activity in the parietal cortex, as if it were working harder” and less activity in the frontal lobes. Berns' hypothesis is that the subject worked harder to see differently and that "the group's answers took some of the load off the decision-making process in the frontal lobe." "In the case of conformity the virtual image beat out the image originating from the subject's own eyes.” (Berns, 2008: 96-97).

When the subject gave the correct answer against the "unanimously wrong group" there was increased activity in the amygdala. Berns' speculation is that "nonconformity underscored the unpleasant nature of standing alone-even though the individual had no recollection of it. In many people the brain would rather avoid activating the fear system and just change perception to conform with the social norm” (Berns, 2008: 95-97).

When people reappraise emotional circumstances, "the prefrontal cortex...inhibits the amygdala... A recent fMRI study found that when people successfully reappraised emotional scenes, meaning they replaced a negative reaction with a positive one, activity in the left prefrontal cortex increased, in an amount that correlated with the decrease in the amygdala” (Berns, 2008: 79). The possibility for reappraisal of a situation and increased exercise of control seems to be dependent on the development of the prefrontal cortex which, as cited by Decety and Lamm, continues to mature to adolescence.

\subsection{Possible Consequences}

Fear can change what one sees; it can cause the person to freeze, a form of paralysis; it can cause an aversive reaction of disconnection and flight; it can impose conformity against judgment.

We have seen in the discussion of empathy that initial empathic reaction can undergo emotional reappraisal. Voluntary control that taps into executive functions of the prefrontal cortex can provide the opportunity to reevaluate an emotional reaction. To do so requires a developed prefrontal cortex and hard work to respond appropriately.

\section{Tentative Understandings}

In the beginning of this paper I asked some questions about caring behavior among humans. Where does it come 
from? What are the manifestations? How and when is it a force for good, or not? Does caring behavior necessarily imply a moral sensibility?

Continuing scientific investigations confirm the reality of the altruistic impulse. At this point there is substantial agreement that the impulse derives from and is an expansion of the mother-child relationship necessary for survival. It is true that fear can prevent one from experiencing caring behavior; too strong identification can cause aversive reactions; obviously, self-interest can top caring. However, the hopeful conclusion is that we are created as human creatures to care about others. And we have the capability of using that caring for moral ends "To do unto others as we would have them do unto us". We also have the capability of emotional reconsideration, so that empathy does not necessarily mean that the initial caring impulse prevails. We can review, rethink and then act.

\section{References}

Batson, D. C. (2012). The Empathy Altruism Hypothesis: Issues and Implications. In J. Decety (Ed.), Empathy from Bench to Bedside, Cambridge: MIT Press.

Berns, G. (2008). A Neuroscientist Reveals How to Think Differently: Iconoclast. Cambridge: Harvard Business Press.

De Schrijver, J. (2009). An Evolutionary and Cognitive Neuroscience Perspective on Moral Modularity. In J. Verplaetse et al. (eds.), The Moral Brain: Essays on the Evolutionary and Neuroscientific Aspects of Morality, New York: Springer Science + Business Media.

Decety, J., \& Lamm, C. (2006). Human Empathy through the Lens of Social Neuroscience. The Scientific World Journal, Ltd., 6, 1146-1163. www.thescientificworld.com.

FitzPatrick, W. (2012). Morality and Evolutionary Biology. In E. N. Zalta (Ed.), The Stanford Encyclopedia of Philosophy (Summer 2012 Edition). http://plato.stanford.edu/archives/sum2012/entries/morality-biology/

Flanagan, O. (2002). The Problem of the Soul. New York: Basic Books.

Hatfield, E., Cacioppo, J. T., \& Rapson, R. L. (1994). Emotional Contagion. Cambridge [England]: Cambridge University Press.

Moll, J., \& de Oliveira-Souza, R. (2009). Extended Attachment and the Human Brain: Internalized Cultural Values and Evolutionary Implications. In J. Verplaetse et al. (Eds.), The Moral Brain: Essays on the Evolutionary and Neuroscientific Aspects of Morality, New York: Springer Science + Business Media.

Pfaff, D. W. (2007). The Neuroscience of Fair Play Why We Usually Follow the Golden Rule. New York: Dana Press

Verplaetse, J., Braeckman, J., \& De Schrijver, J. (2009). Introduction. In J. Verplaetse et al. (Ed.), The Moral Brain: Essays on the Evolutionary and Neuroscientific Aspects of Morality, New York: Springer Science + Business Media.

Zahavi, D., \& Overgaard, S. (2012). Empathy without Isomorphism: A Phenomenological Account. In J. Decety (Ed.), Empathy from Bench to Bedside, Cambridge: MIT Press. 
Scientific Research Publishing (SCIRP) is one of the largest Open Access journal publishers. It is currently publishing more than 200 open access, online, peer-reviewed journals covering a wide range of academic disciplines. SCIRP serves the worldwide academic communities and contributes to the progress and application of science with its publication.

Other selected journals from SCIRP are listed as below. Submit your manuscript to us via either submit@scirp.org or Online Submission Portal.
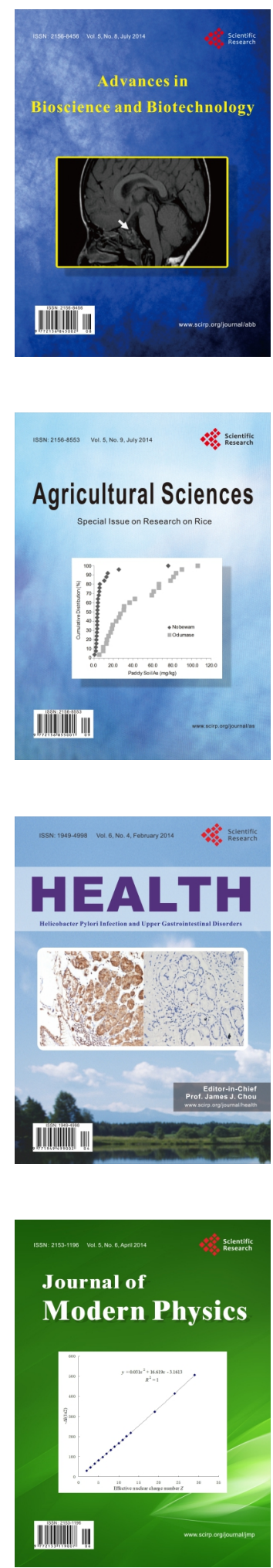
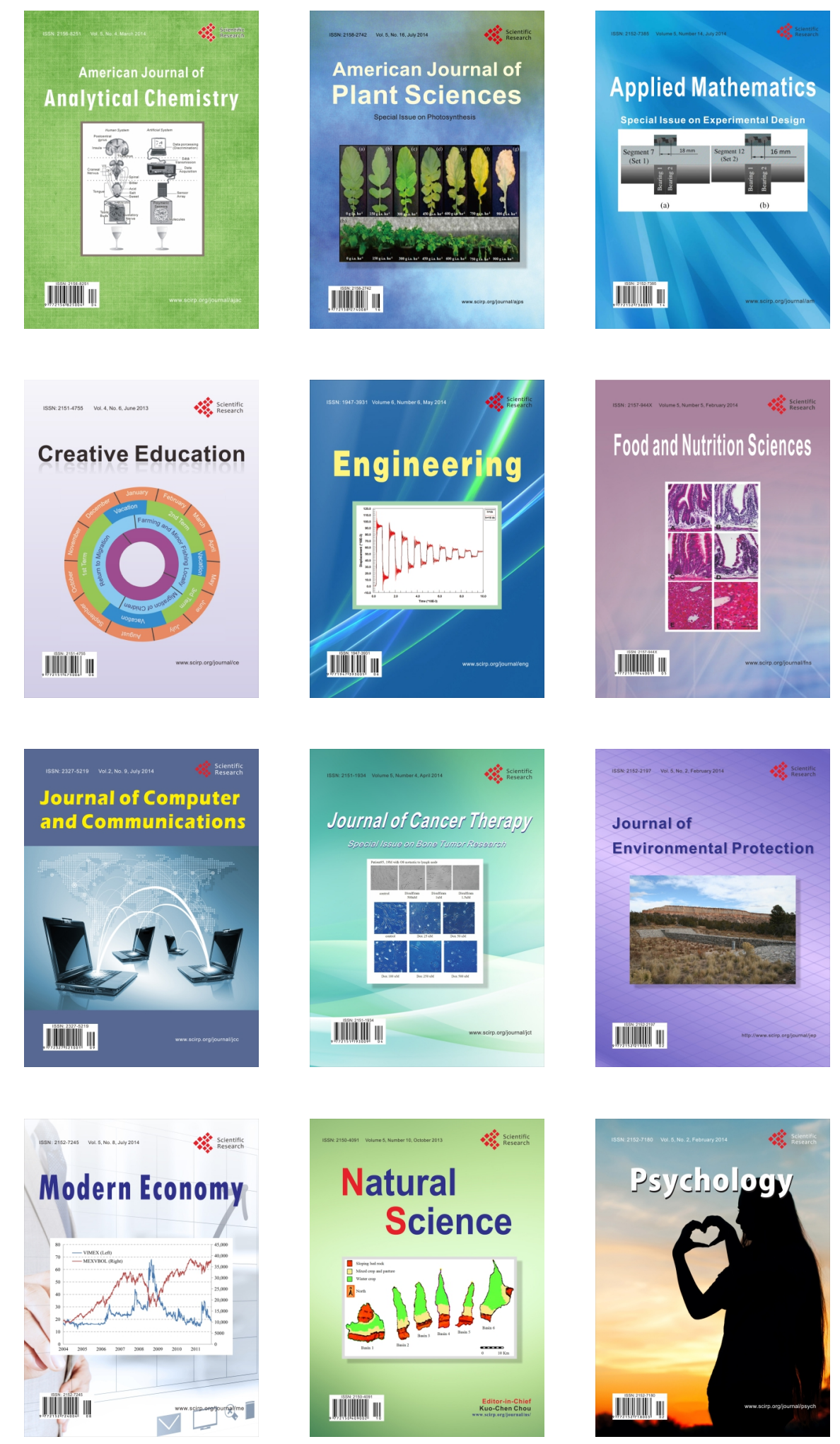